\title{
Large calcified right atrial myxoma in a newborn Rare cause of neonatal death
}

\author{
SINDA B DIANZUMBA, GURENDRA CHAR \\ From the Departments of Medicine (Cardiology) and Pathology, University Hospital of the West Indies, Kingston, \\ Famaica
}

SUMMARY A newborn baby girl presented at birth with severe cyanosis, congestive cardiac failure, and an ischaemic leg ulcer, and died within 10 hours of birth. Necropsy disclosed a large haemorrhagic, calcified right atrial myxoma obstructing the tricuspid valve.

Right atrial myxoma is a rare cause of heart failure in infancy and childhood. ${ }^{1-4}$ Since its clinical diagnosis is elusive in this age group, ${ }^{4}$ it is usually not suspected in the differential diagnosis of cyanotic neonates with congestive cardiac failure. The implications, however, of making the diagnosis of this potentially curable tumour during life are obvious. We report a newborn baby with a calcified right atrial myxoma simulating cyanotic congenital heart disease.

\section{Case report}

A 19 year old primigravida was admitted to the University Hospital of the West Indies maternity ward with severe pre-eclampsia and hydramnios at 30th week of pregnancy. Her blood group was A, Rh positive. Four weeks after admission, fetography was normal. Eight weeks later spontaneous rupture of the membranes occurred. She was transferred to the labour ward for induction and thirty hours later a female child, weighing $3025 \mathrm{~g}$, was born. The baby was cyanotic and had generalised oedema with a bloated abdomen. She had no spontaneous cry. Respirations were forced and gasping in type. Since no resuscitative measures were undertaken, the baby died 10 hours after delivery. The placenta was large, oedematous, and fragmented. Necropsy showed that the lungs and liver were congested and the right atrium and ventricle were enlarged. There was a large glistening, pedunculated tumour (measuring $2 \times 2 \times 1.8 \mathrm{~cm}$ ) attached to the endocardium of the posterior wall of the right atrium (Fig. 1), completely obstructing the tricuspid valve orifice. Its surface was haemorrhagic and ulcerated. The cut sections of the tumour showed multiple areas of haemorrhages and calcification. Histology and special stains confirmed the tumour to be a myxoma (Fig. 2). There was a moderate amount of ascitic fluid in the abdomen and

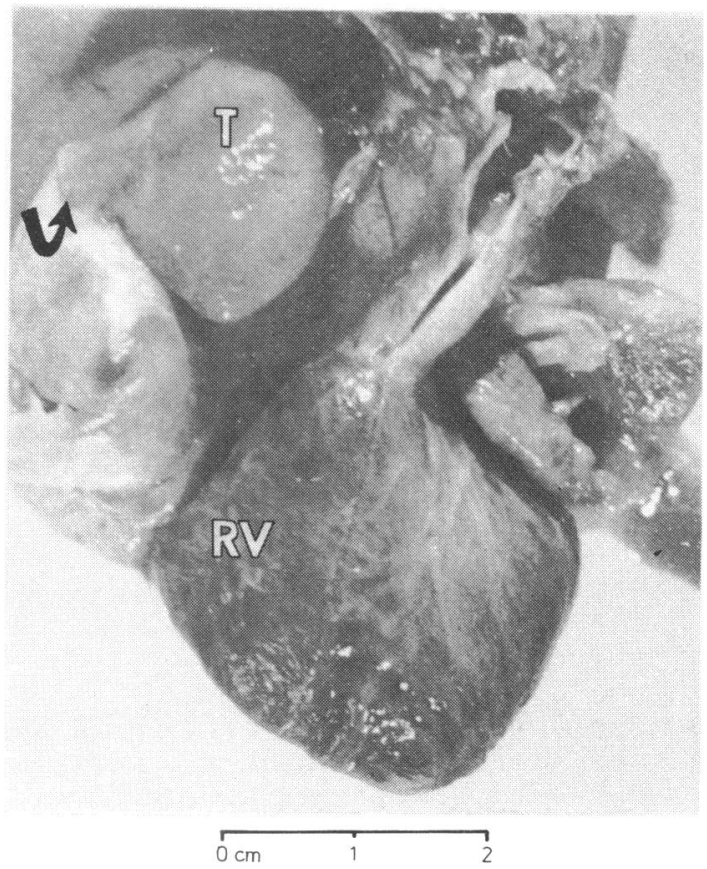

Fig. 1 Gross specimen of the heart depicting the tumour (T) within a dilated opened right atrium, arising from the endocardium of the posterior atrial wall. The arrow points to the pedicle of the tumour on the endocardial surface. $R V$, unopened right ventricle. 
an ischaemic ulcer of the left foot was also noted. The latter was thought to be a result of a paradoxical embolus which appeared to have occurred in utero.

\section{Comments}

A right atrial myxoma, like the commoner left atrial myxoma, usually causes symptoms and signs of obstruction. ${ }^{5}$ Our patient is the youngest reported pres- enting with a calcified tumour. At birth she showed cyanosis, congestive cardiac failure, anasarca, as well oᄋ as an ischaemic ulcer on her leg, presumably the $\mathbb{D}$ result of paradoxical systemic embolus through a patent foramen ovale. Unfortunately she did not live long enough to undergo appropriate investigation.

This presentation emphasises the fact that right $\stackrel{\odot}{\stackrel{D}{\circ}}$ atrial myxoma can be a rare cause of fatal neonatal $\unrhd$ cyanotic heart failure. The tumour was extremely 
large relative to the baby's heart size and undoubtedly produced severe obstruction to right ventricular filling, leading to a low cardiac output and severe right heart failure. The mild hypertrophy of the right ventricle which was present also suggests associated tricuspid regurgitation, which is found with calcified right atrial myxoma. ${ }^{3}$ With modern diagnostic methods and improved surgical techniques, this lesion may be successfully treated if the diagnosis is suspected. ${ }^{3-5}$ Cardiac tumours such as atrial myxomas are now readily diagnosed by $\mathbf{M}$-mode echocardiography and particularly two dimensional real time echocardiography where movement, shape, and location can be clearly defined in relation with cardiac structures. ${ }^{6-9}$ Unfortunately this newborn baby was not referred to a cardiologist.

Thus, the unusual features of this case are the age of the baby, the right atrial location of the myxoma, calcification of the myxoma in utero, the large size of the tumour with obstructive signs presenting as severe cyanotic congenital heart disease at birth, probable paradoxical systemic embolisation present at birth, and an apparent extremely rapid growth of the myxoma in utero.

We thank Professor Vasil Persaud, Department of Pathology, for reviewing the slides of the myxoma.

\section{References}

1 Sanyal SK, de Leuchtenberg N, Rojas RH, Stansel HC, Browne MJ. Right atrial myxoma in infancy and childhood. Am f Cardiol 1967; 20: 263-9.

2 Burech DL, Teske DW, Haynes RE. Right atrial myxoma in a child. Am F Dis Child 1977; 131: 750-2.

3 Crawford FA Jr, Selby JH Jr, Watson D, Johansen J. Unusual aspects of atrial myxoma. Ann Surg 1978; 188: $240-44$.

4 Griffiths GC. A review of primary tumors of the heart. Prog Cardiovasc Dis 1965; 7: 465-79.

5 Silverman NA. Primary cardiac tumours. Ann Surg 1980; 191: 127-38.

6 Pernod J, Piwnica A, Duret JC. Right atrial myxoma: an echocardiographic study. Br Heart f 1978; 40: 201-3.

7 Come PC, Kurland GS, Vine HS. Two-dimensional echocardiography in differentiating right atrial and tricuspid valve mass lesions. Am $\mathcal{f}$ Cardiol 1979; 44: 1207-12.

8 Bommer WJ, Kwan OL, Mason DT, DeMaria AN. Identification of prominent eustachian valves by $M$-mode and two dimensional echocardiography: differentiation from right atrial masses (abstract). Am f Cardiol 1980; 45: 402 .

9 Feigenbaum H. Echocardiography. 3rd ed. Philadelphia: Lea \& Febiger, 1981: 514-6.

Requests for reprints to Dr Sinda B Dianzumba, Department of Medicine (Cardiology), University of the West Indies, Kingston 7, Jamaica, West Indies. 